\title{
The effect of supportive care program based on Bandura self-efficacy on stress- exacerbating and stress-relieving factors of neonatal mothers admitted to neonatal intensive care unit
}

\author{
Shima Heidary ${ }^{1}$, Haydeh Heidari ${ }^{1 *}$, Roya Choopani ${ }^{2}$, Morteza Sedehi ${ }^{3}$ \\ 1. Faculty of Nursing and Midwifery, Shahrekord University of Medical Sciences, Shahrekord, Iran \\ 2. Shahrekord University of Medical Sciences, Shahrekord, Iran \\ 3. School of Health, Shahrekord University of Medical Sciences, Shahrekord, Iran
}

Received: 7 May 2021

Accepted for publication: 31 July 2021

[EPub a head of print-24 August 2021]

Payesh: 2021; 20 (4): 451- 460

\begin{abstract}
Objectives: The birth of a premature baby can change all the emotions of parents and replace stress. It is necessary to identify the factors that aggravate and relieve maternal stress and adopt strategies to reduce it. The aim of this study was to analyze the effect of supportive care program based on Bandura's self-efficacy on aggravating and stress relieving factors of mothers of neonates admitted to the neonatal intensive care unit

Methods: A quasi-experimental study was performed in 2020 on 90 mothers of premature infants admitted to the neonatal intensive care unit of a Hospital in Shahrekord by convenience sampling method. The experimental group has received an educational intervention based on the theory of self-efficacy in four two-hour sessions with the presentation of an educational booklet. Data were collected using a self-designed questionnaire before and after the intervention in both groups and were analyzed using SPSS software version 24 performing paired t-test, independent t-test, and Chi-square.

Results: The results showed that the mean score of stressors in mothers of preterm infants in the control group decreased from $42.73 \pm 6.26$ to $42.62 \pm 7.09$, which was not statistically significant $(\mathrm{P}=0.906)$ while in the experimental group it was decreased from $48.78 \pm 4.36$ to $25.33 \pm 4.84$, which was statistically significant $(\mathrm{P}<0.001)$. The mean score of soothing agents for mothers of preterm infants increased from $2.98 \pm 2.61$ to $3.07 \pm 2.29$ in the control group which was not statistically significant $(\mathrm{P}=0.415)$ and in the experimental group it was increased from $4.51 \pm 1.72$ to $7.29 \pm 1.16$, which was statistically significant $(\mathrm{P}<0.001)$.
\end{abstract}

Conclusion: Based on the findings of the study, it is recommended to implement interventions to make parents of premature infants, especially mothers ready to face the baby in the intensive care unit.

Key words: Stress, mother, newborn intensive care units, care program

\footnotetext{
* $\overline{\text { Corresponding author: Shahrekord University of Medical Sciences, Shahrekord, Iran }}$

E-mail: haydehheidari@gmail.com
} 


\title{
تاثير بر نامه مراقبت حمايتى مبتنى بر خودكار آمدى بندورا بر عوامل تشديدكننده و تسكين دهنده استر سادران نوزادان بسترى در بخش مر اقبت هاى ويزه نوزادان
}

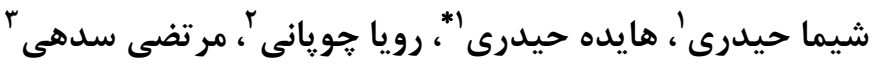 \\ I. دانشكده يرستارى و مامايى، دانشاه علوم بزشكى شهركرد، شهركرد، ايران

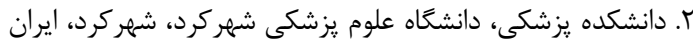

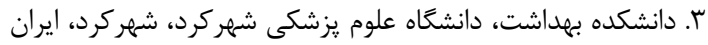

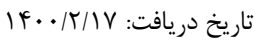

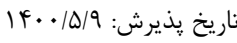

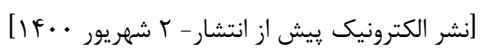

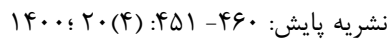

جكيده

مقدمه: تولد نوزاد نارس مى تواند به تمام احساسات خوب والد شدن والدين يايان دهد و استرس را جايكزين كند. شناسايى عوامل تشديد كننده و تسكين

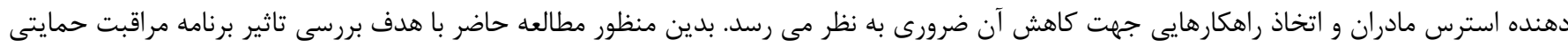

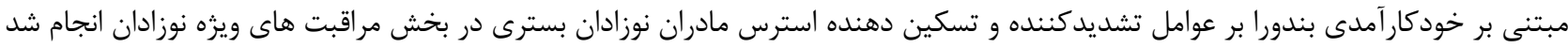

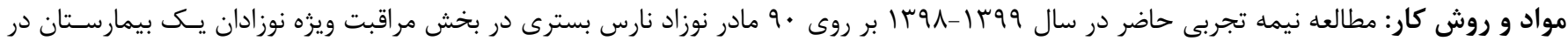

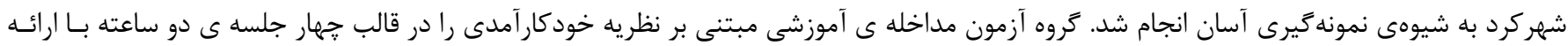

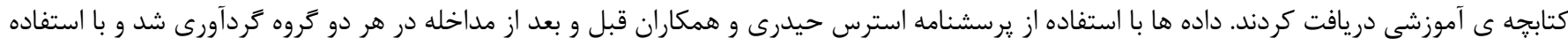

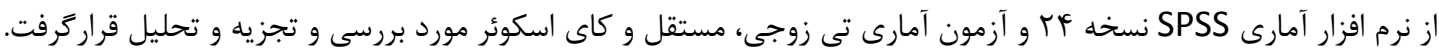

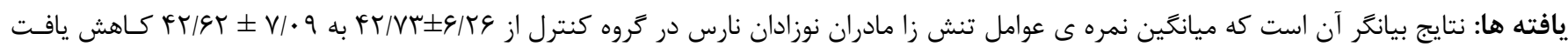

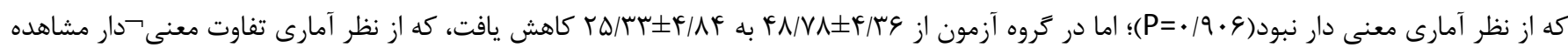

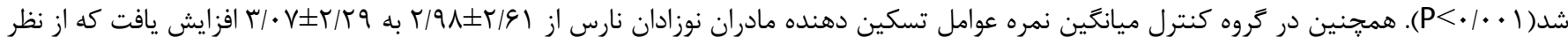

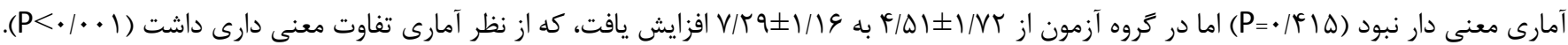

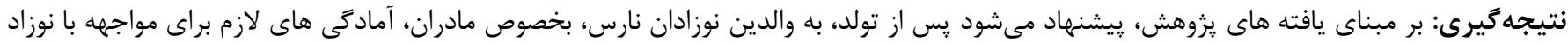

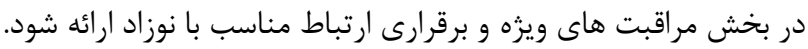
كليدوازه: استرس، مادر، بخش مراقبت ويزه نوزادان، برنامه مراقبتى

كداخلاق: IR.SKUMS.REC.1398.233 
نوزادشان و اهميت فراهم نمودن فرصت براى وابستخى و يِيوستـتى

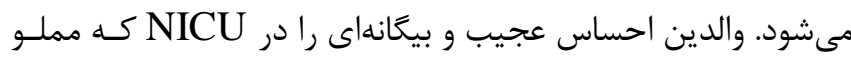

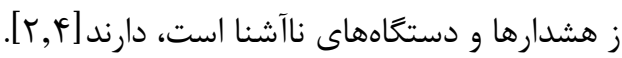
يكى از نقشهاى يرستار كمك به مادر براى ايجـاد احسـاس مطلـع

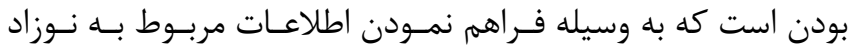

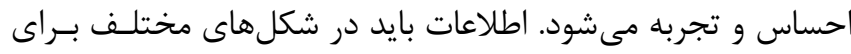
استفاده به وسيله انتقال از راههاى كَونـاكون ارائـه شـود. بـهـ عنــوان

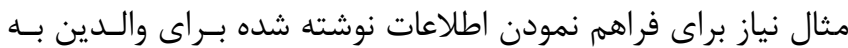

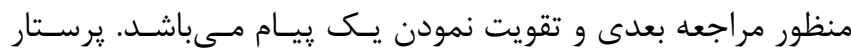

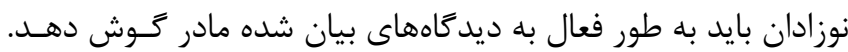

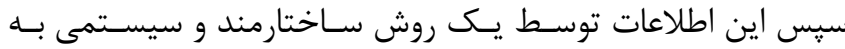

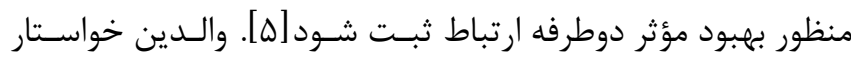

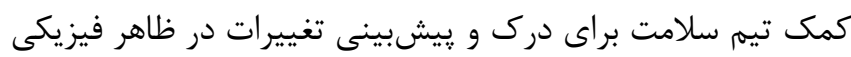

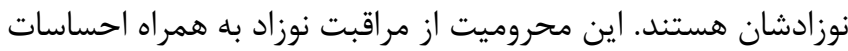

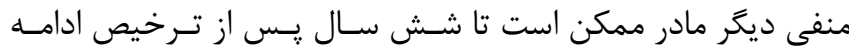

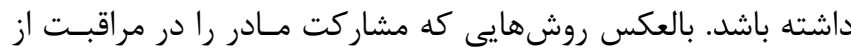
نوزادش تشويق نمايد، يا مادر به عنوان يك فرد رفتار كرده و ارتباط

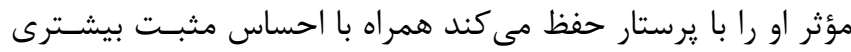

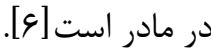
حمايت فراهم شده توسط تيم سلامت براى كمك به ساز كارى مادر

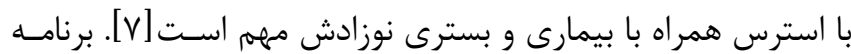

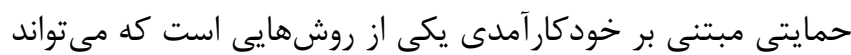

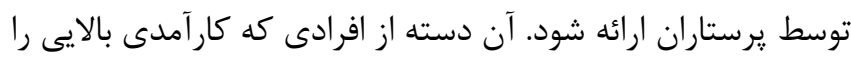

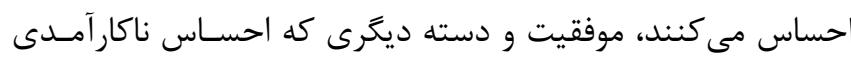

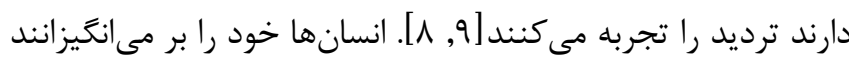

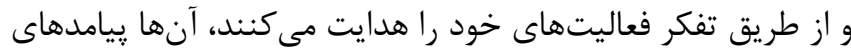

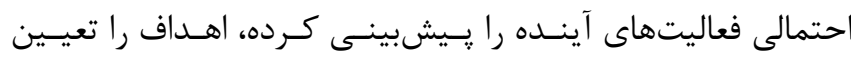

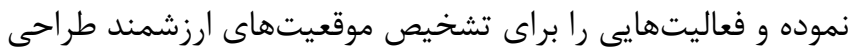

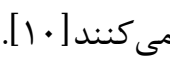
راهبرد ملموسى بايد در NICU با هدف بهينه سازى شرايط حضور والدين در مراقبت از نوزاد تدوين شود. مداخلاتى در جهت شناسايى داسيى عوامل تنش زاو تسكين دهنده استرس براى مـادران بـهـ يرسـتاران

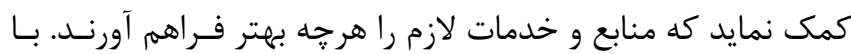
توجه به كمبود نيروى يرستارى و حجم كارى بالا در NICU زمان

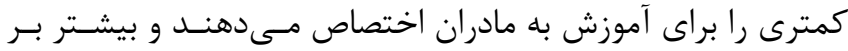
مراقبت از نوزاد نارس تمركز مى كنند. اين درحالى است كه حمايـت

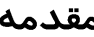

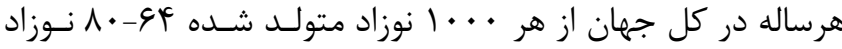

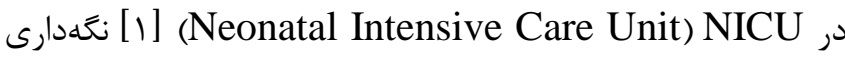
مىشوند. ايران نيز جزء مناطق با شيوع بالاى زايمـان زودرس اسـت

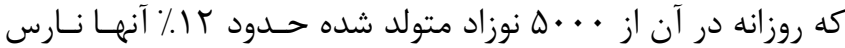

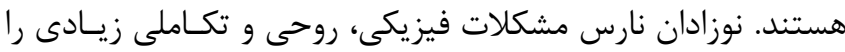

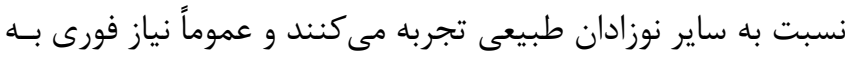

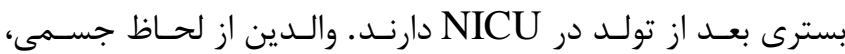

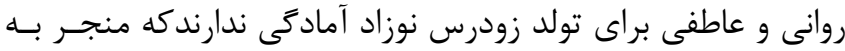

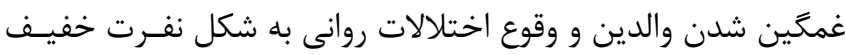

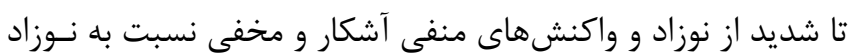

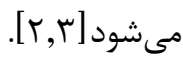

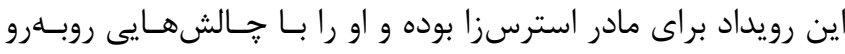

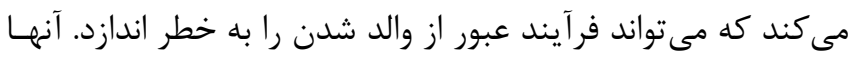

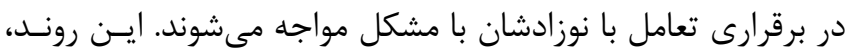

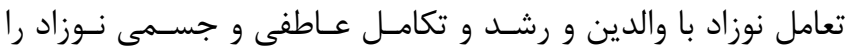

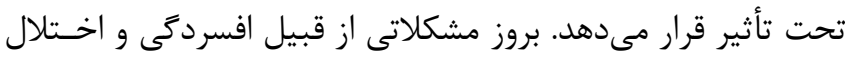

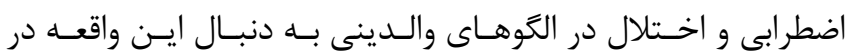

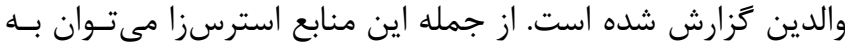

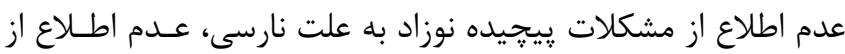

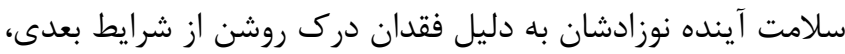

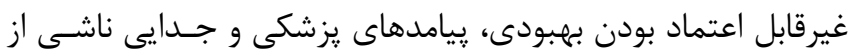

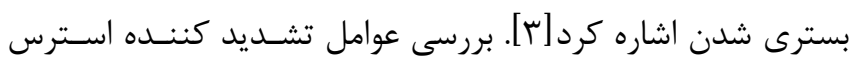

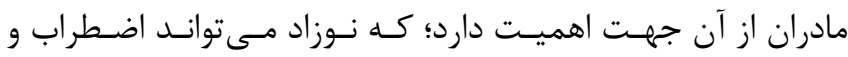

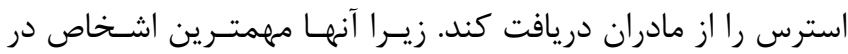

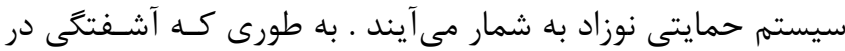

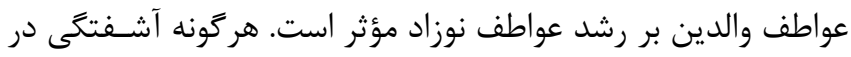
خلق والدين مىتواند بر نوزاد تأثير منفى داشته باشد [ع].

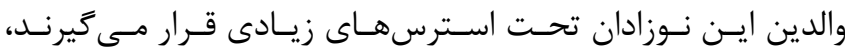
يرستاران نقش حياتى در كمك به والدين در رابطه با تجربه استرس

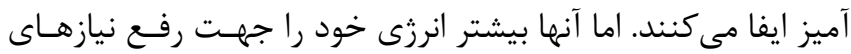

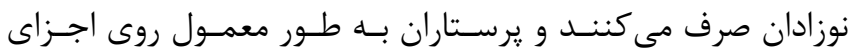
تكنيكى مراقبت بالينى نوزاد تمركز دارند و والدين مورد توجـهـ قـرار

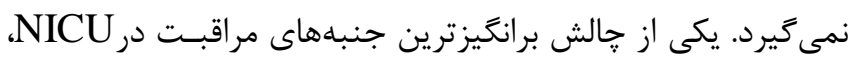

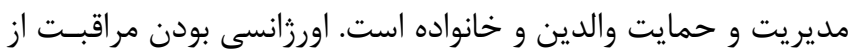
نوزاد، باعث شناخت كمى از نقش منحصر به فرد مـادران در بهـبـود 


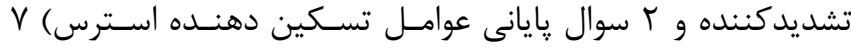

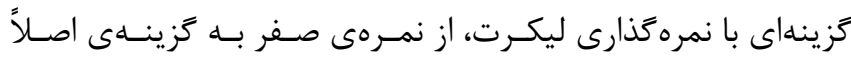

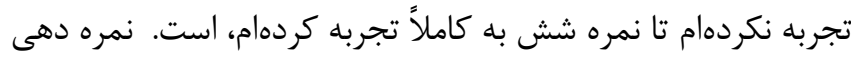

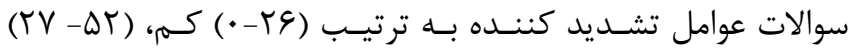

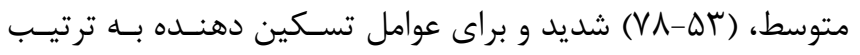

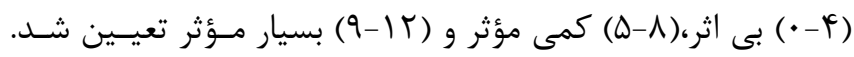

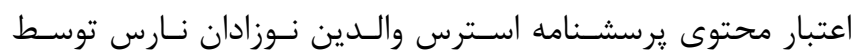
حيدرى و همكاران در سال در اصفهان توسط صاحب نظران VA/ • و

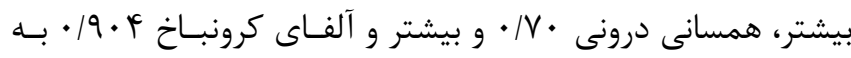

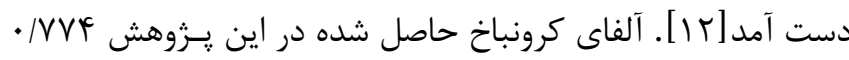

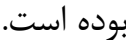

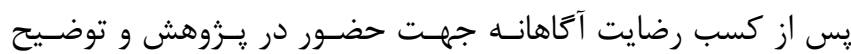

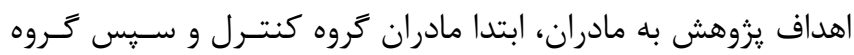

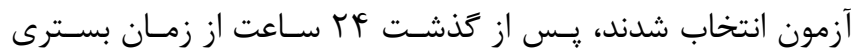
نوزادان در NICU و يك ساعت قبل از مستقر شدن مادر در بخش إنش NICU

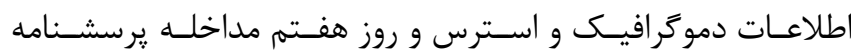
استرس يس از مداخله توسط فردى غير از يزوهشكر تكميل گرديد.

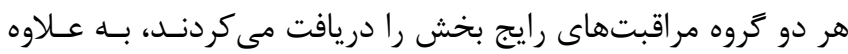

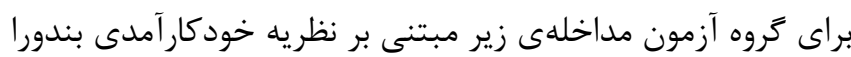

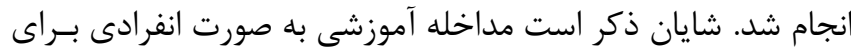
هر نفر از مادران كروه آزمون توسط يزوهشكر ارائه كرديد.

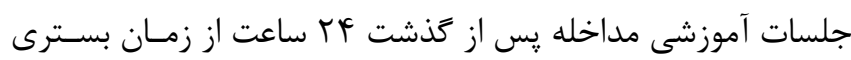

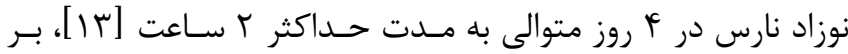
اساس جهار مرحلهى تئورى خودكارآمدى بندورا در ع جلسه بركزار كرديد، عبارتند از: تجربه عملكردى(حمايت ابزارى): تجربه عملكـردى در سـاز كارى بـاــا

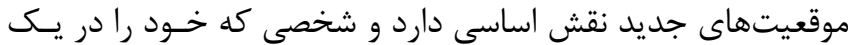

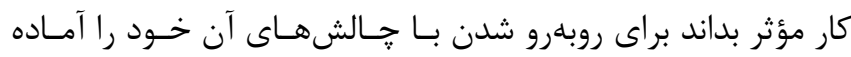

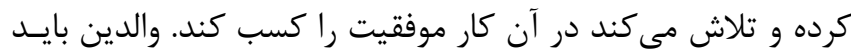

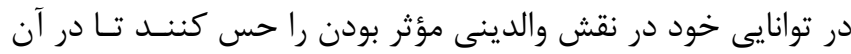

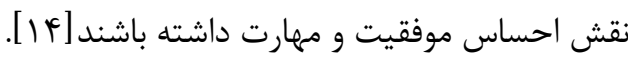

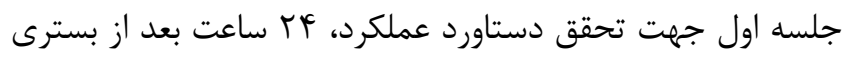

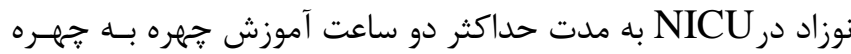

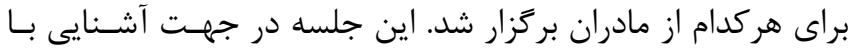

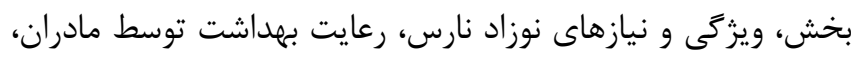

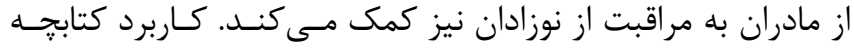

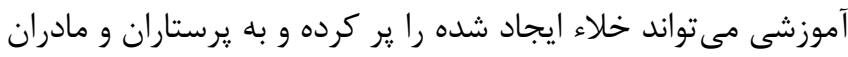

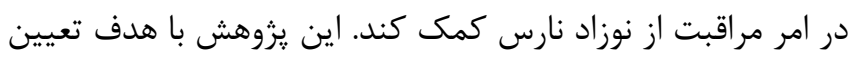

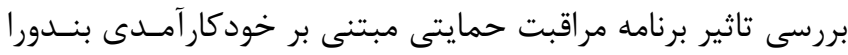

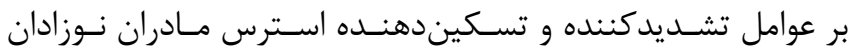
بسترى در بخش مراقبتهاى ويزه نوزادان انجام شد.

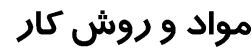

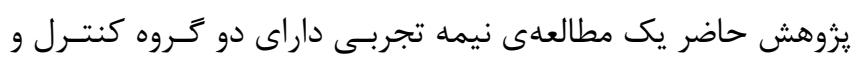

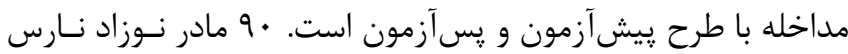

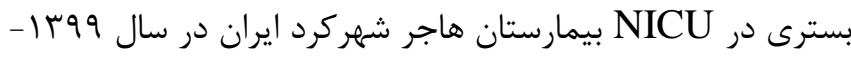

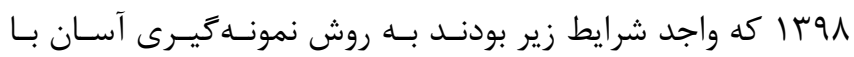

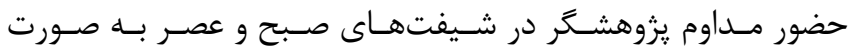

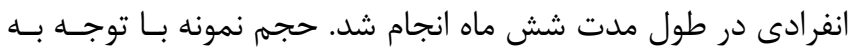

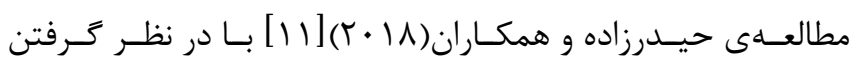

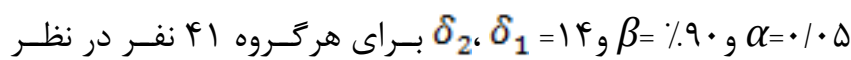

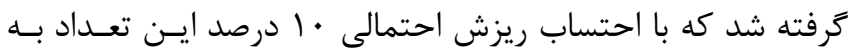

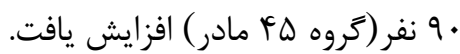

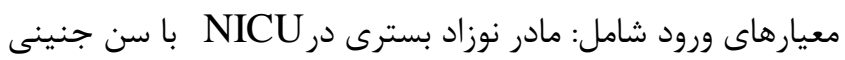

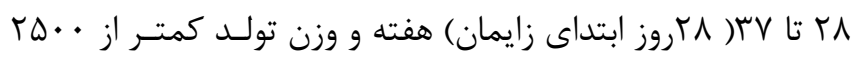

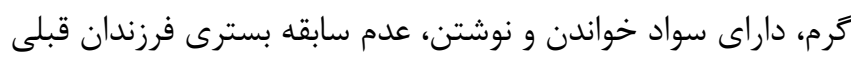

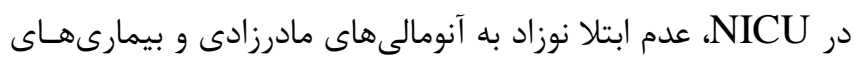
جسمى مازور، عدم وجود نقص نورولوزيك شامل تشنج، عدم سـابقه إنه

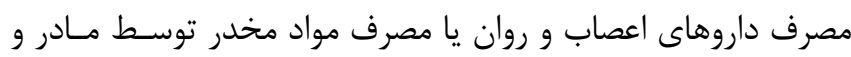

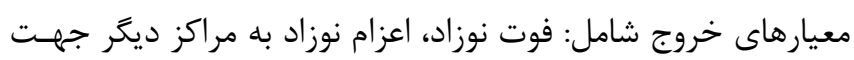

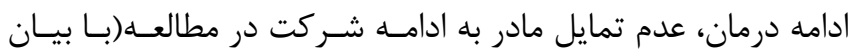

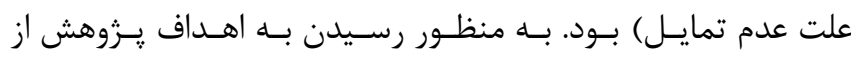

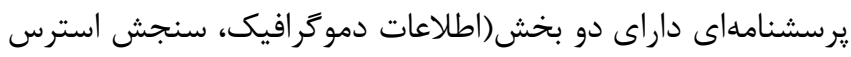
مادران) استفاده شد.

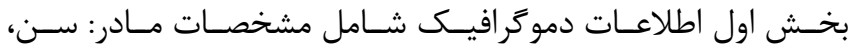

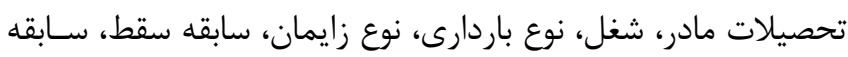

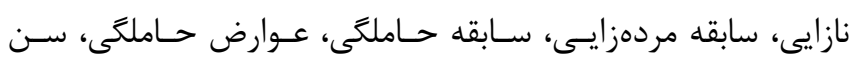

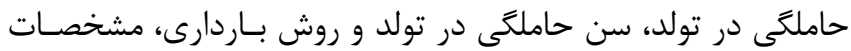

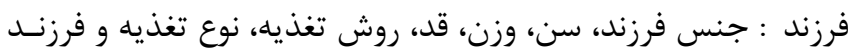

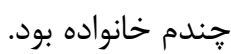

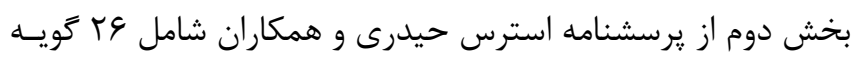

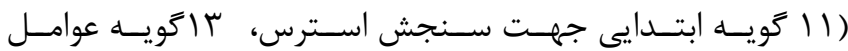


ادراكات بر قضاوت آنها از توانايىشان اثركذار است. حالات عاطفى و

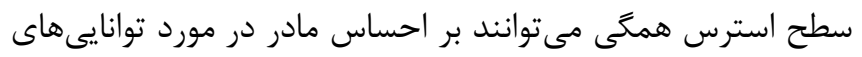

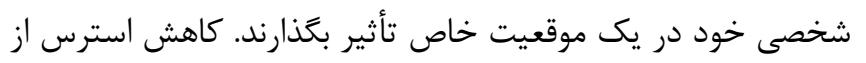

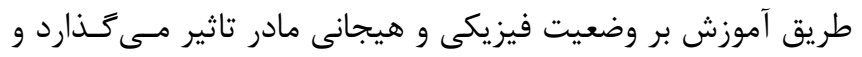

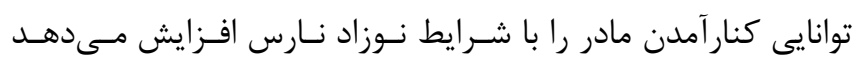
[r $[r-r \Delta]$

جلسه جهارم براى تحقق مرحلهى توجه به واكنشهـاى هيجـانى و

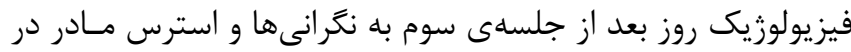

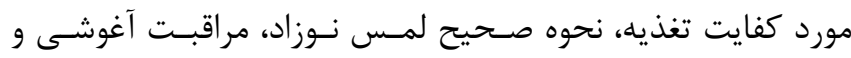

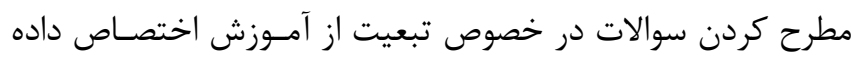

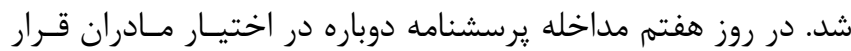

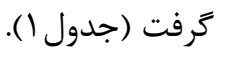

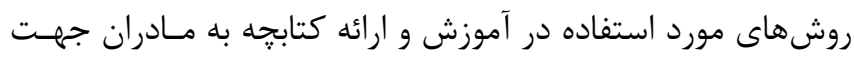
ارتقاى اطلاعات و دانش شامل آموزش جهره به جهره، ايفاى نقش،

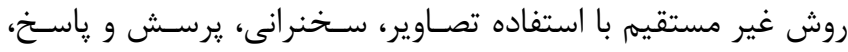

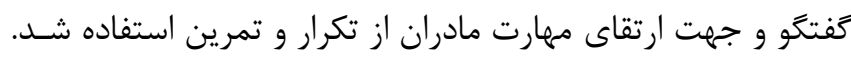
جهت ارتقاى ارتباطات كفتتارى و نوشـتارى از بيـان سـاده و شـفاف

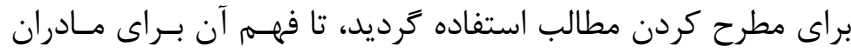
راحتتر باشد. جهت ايجاد بهبود سيستم حمايتى بـراى مـادران، در مر كران

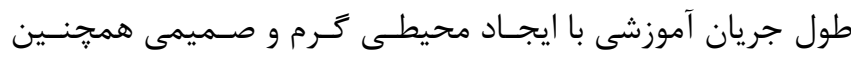

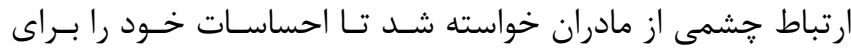

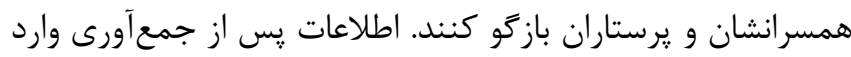

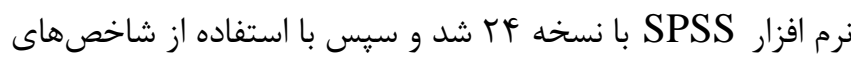
مركزى و يراكندگى، آزمون تى مستقل، زوجى و كاى اسكوئر تجزيه

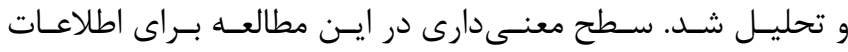

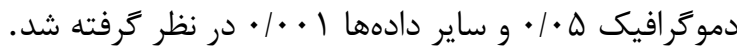

\section{يافتهها}

كروه كنترل و مداخله هركدام شامل هُ نه نفر از مادران نوزادان نارس

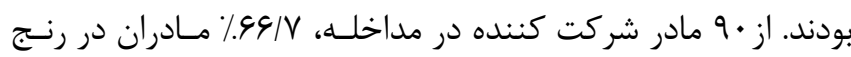

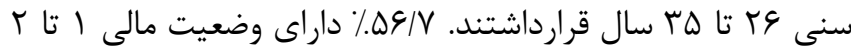

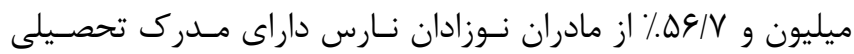

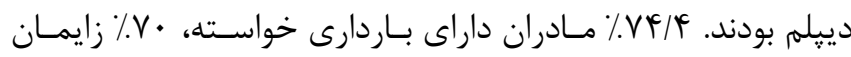

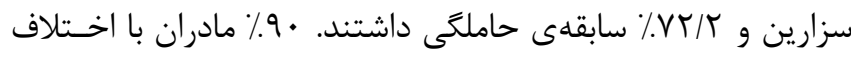
معنى دارى سابقهى نـازايى (F

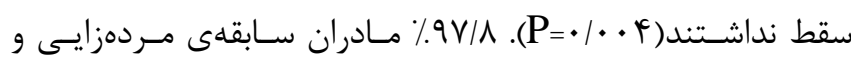

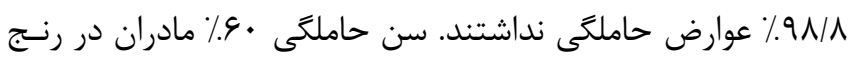

آموزش درك رفتار نوزاد، رفتار مراقبتى و مراقبت آغوشى به مادران

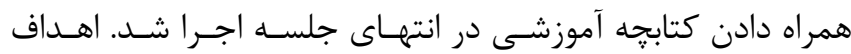

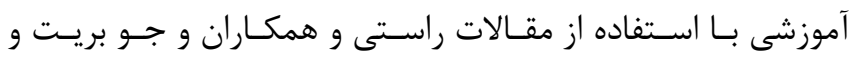

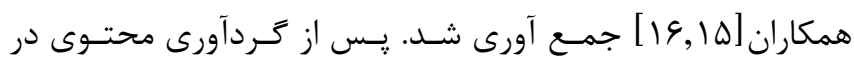

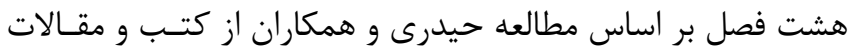

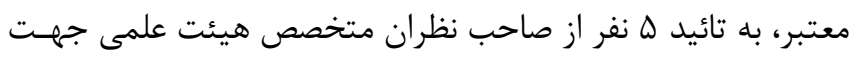

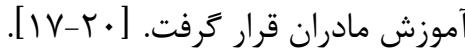

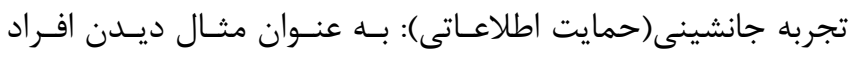

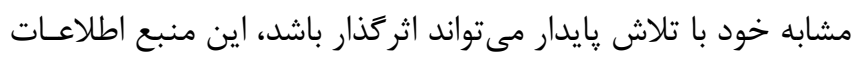

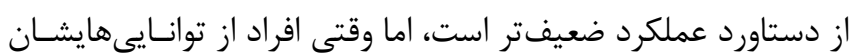

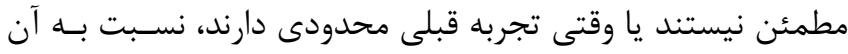
حساستر مىشوند. مطالعات متعددى با استفاده از فـيلم و مشـاهده

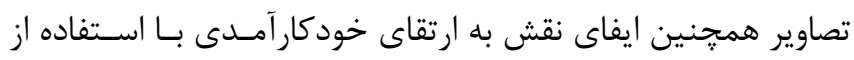

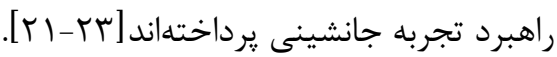

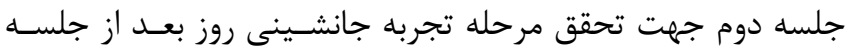

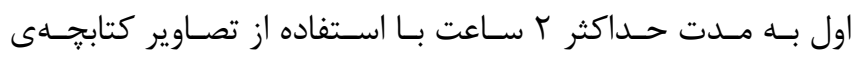
آموزشى و ماكت به آموزش نحوهى صحيح يوزيشن دادن بـهـ نــوزاد

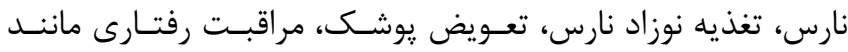

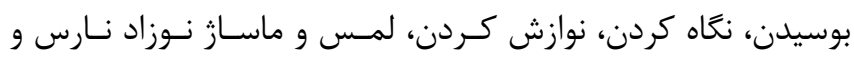
تماس نزديك با نوزاد نارس يرداخته شدان ترغيب كلامى (حمايت عاطفى): قانعسازى كلامى رايجترين ترغيـب

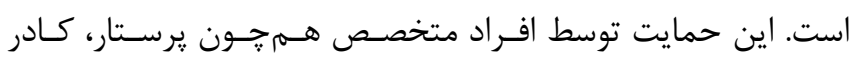

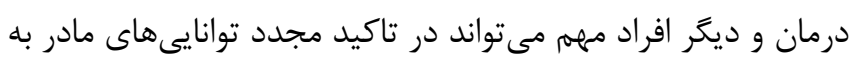

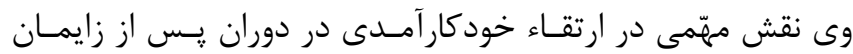

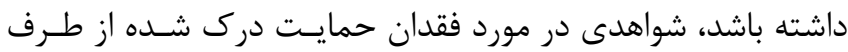

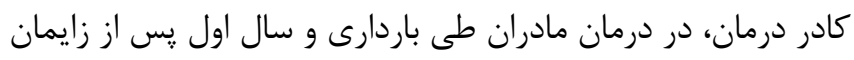

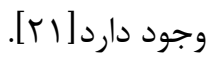

جلسه سوم جهت تحقق مرحله تشويق كلامى روز بعد از جلسه دوم

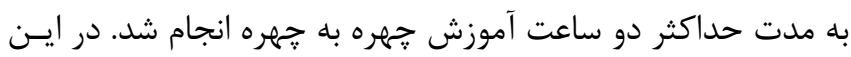

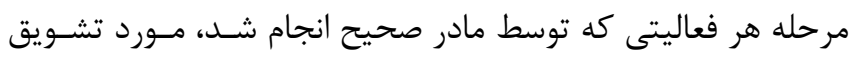
توسط يزوهشكر قرار گرفت و در صـورت نادرسـت بـودن، اقـدامات

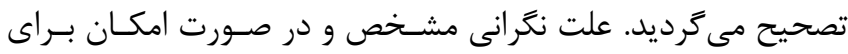
كاهش نكرانى راهكار به مادران ارائه شد.

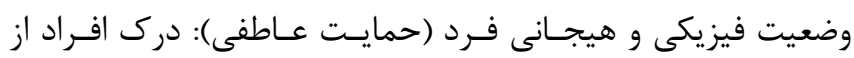

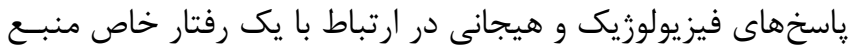

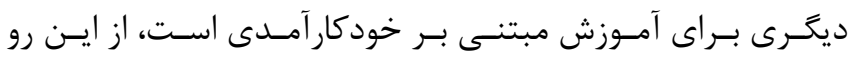


نشريه يروهشكده علوم بهداشتى جهادانشگاهى

نتايج اين مطالعه نشان دادند عوامل تنشززا اسـترس مـادران نـوزادان

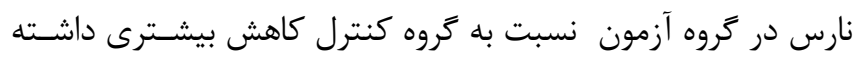

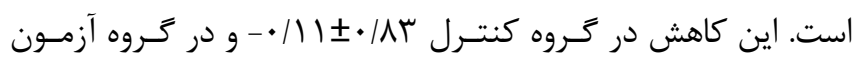

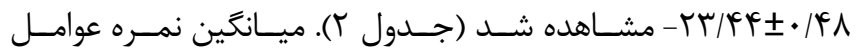

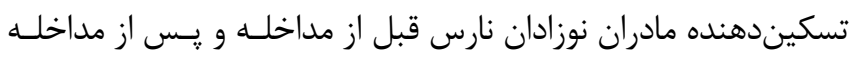

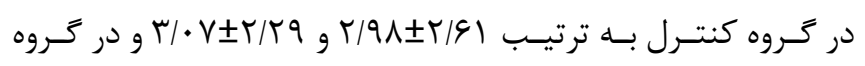

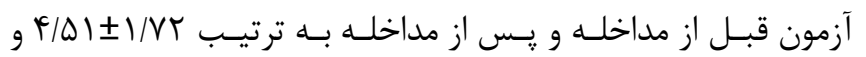

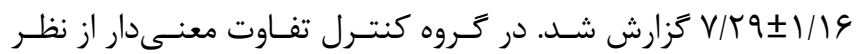

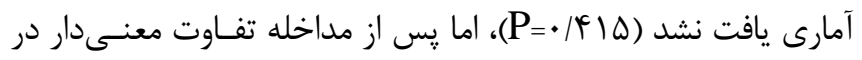

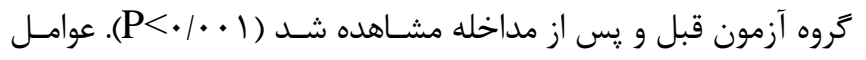

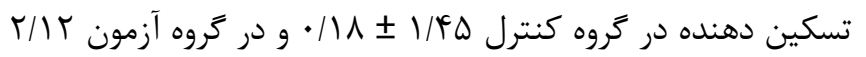

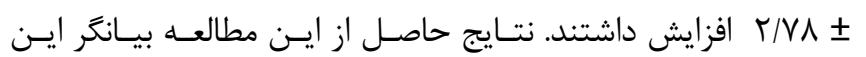

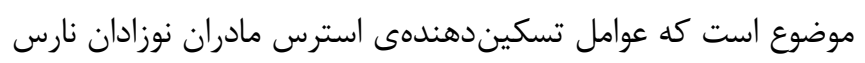

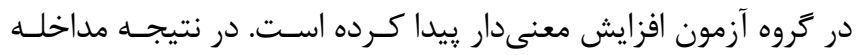

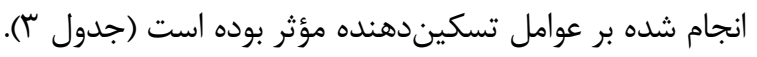

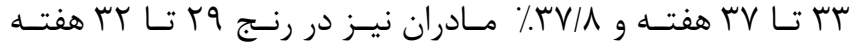

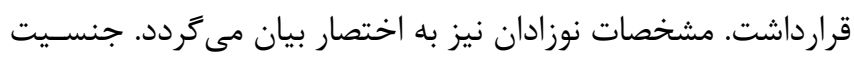

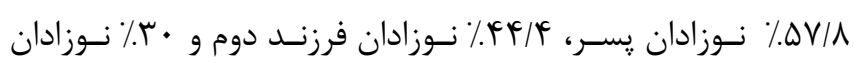

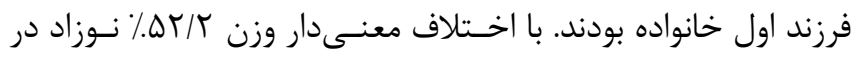

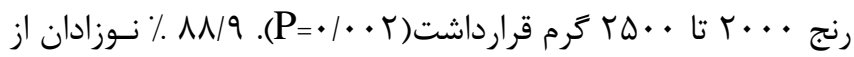

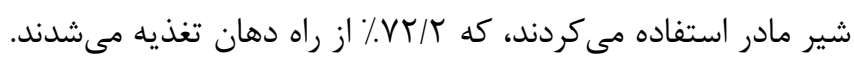

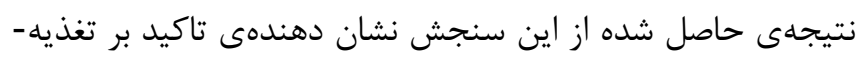
ى انحصارى با شير مادر در بيمارستانها ايران اسـت. تمـام مـادران

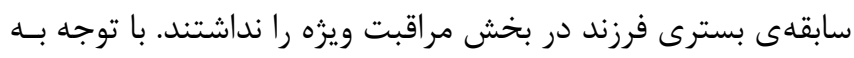

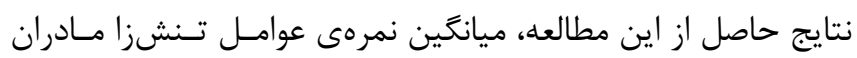

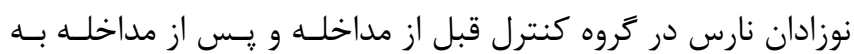
ترتيب

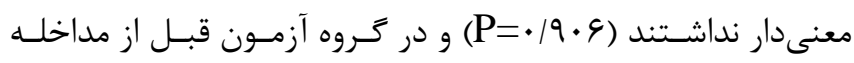
آ

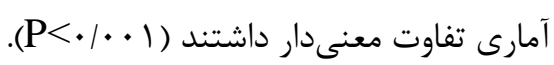

جدول ا: (جلسات آموزشى)

\begin{tabular}{|c|c|c|c|}
\hline مدت زمان آموزش & روش آموزشى & محتوى آموزشى & \\
\hline حداكثر r ساعت & آموزش فرد به فرد & 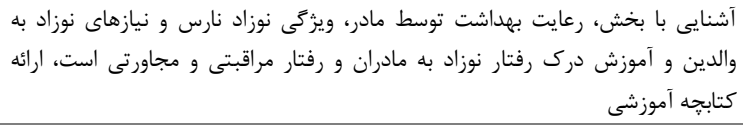 & (ملسه اول \\
\hline حداكثر r ساعت & 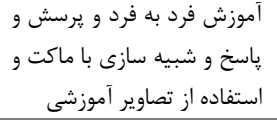 & 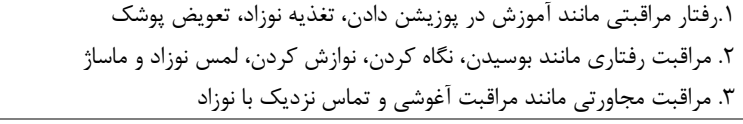 & 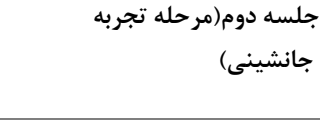 \\
\hline حداكثر r ساعت & نوزاد و تشويق كلامى فرد بر بالين & ادامه آموزشها به صورت عملى در جهت كسب تجربه و استفاده از ترغيب كلامى & (تشويق كلامى) \\
\hline حداكثر r ساعت & واكنش مادر فرد به فرد و توجه به & بيان احساسات و سوالات درخصوص تبعيت از آموزش را بيان كنند & 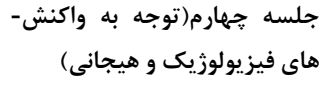 \\
\hline
\end{tabular}

جدول r: ميانكَين نمره عوامل تنشزا استرس مادران نوزادان نارس در كروه كنترل و آزمون، يِيش و يس از مدان مداخله

\begin{tabular}{|c|c|c|c|}
\hline$P$ value & يس آزمون(ميانكين_ذانحراف معيار) & ييش آزمون(ميانكيند|نحرافمعيار) & \\
\hline $\mathrm{P}=\cdot / 9 \cdot 9$ & FY/GY $\pm V / .9$ & FT/VTE \pm G/KG & 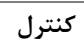 \\
\hline $\mathrm{P}<\cdot / \cdot . \cdot 1$ & $r \Delta / r r \pm F / \Lambda F$ & $F / V N \pm F / T G$ & مداخله \\
\hline
\end{tabular}

جدول ": ميانكين نمره عوامل تسكين دهنده استرس مادران نوزادان نارس در كروه كنتر ل و آزمون، بيش و پيس از مداخله

\begin{tabular}{|c|c|c|c|}
\hline P value & يس آزمون(ميانكين \انحراف معيار) & يِيش آزمون(ميانكين士|نحرافمعيار) & \\
\hline $\mathrm{P}=\cdot / 9 \cdot 4$ & $r / \cdot V \pm r / r q$ & $r / 9 \Lambda \pm r / 91$ & كنترل \\
\hline $\mathrm{P}<\cdot / . .1$ & $V / \pi q \pm 1 / 19$ & $r / \Delta I \pm 1 / V r$ & مداخله \\
\hline
\end{tabular}




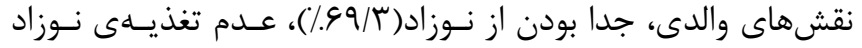

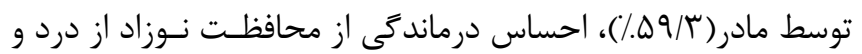

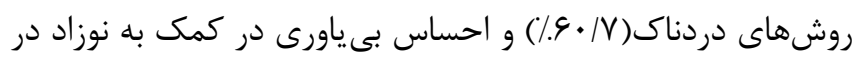

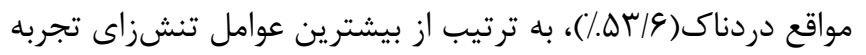

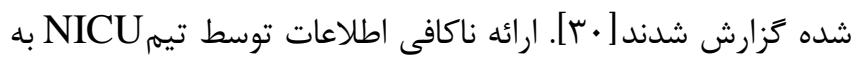

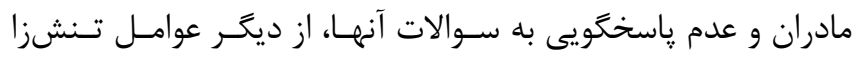

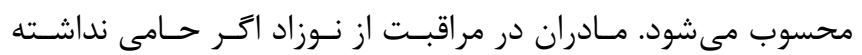

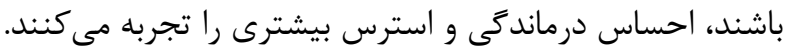

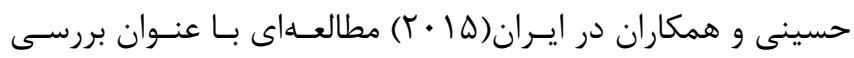

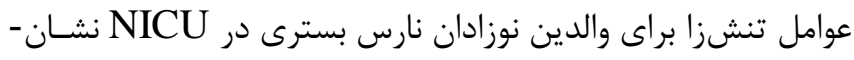

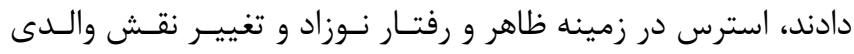

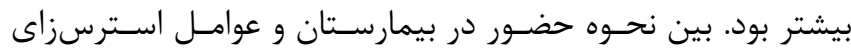

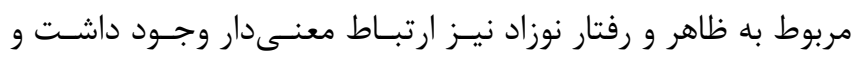

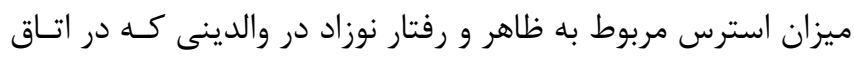

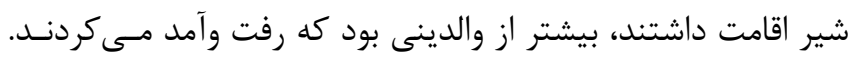

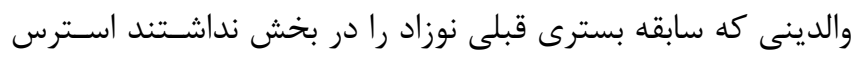

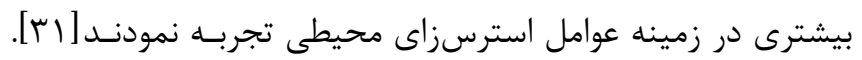

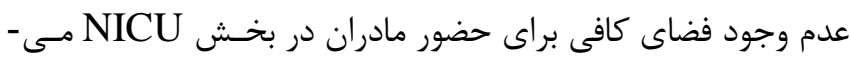

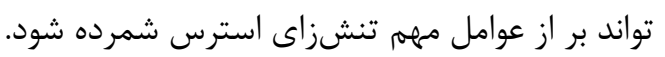

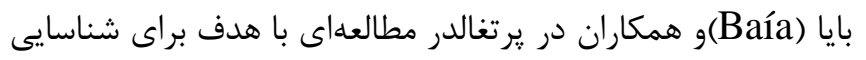

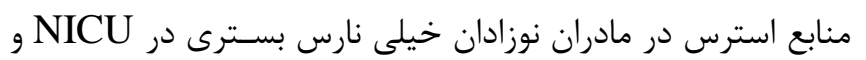

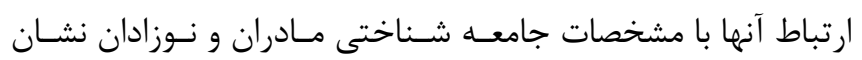

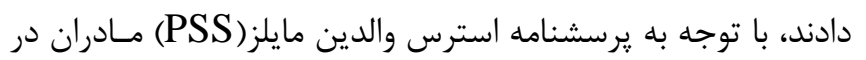
همه خرده مقياسها به طور قابل توجهى استرس بالايى داشتند، اما

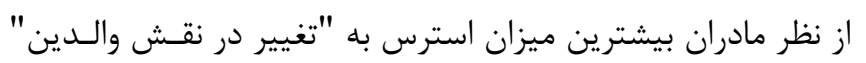

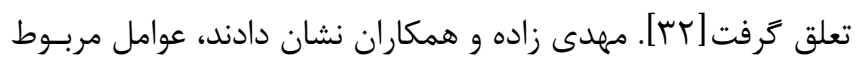

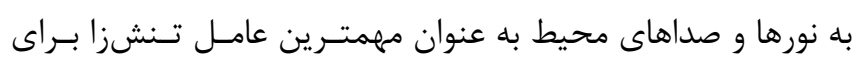

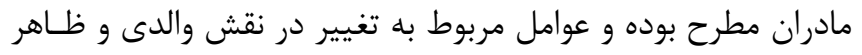

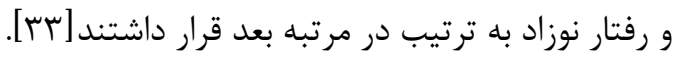

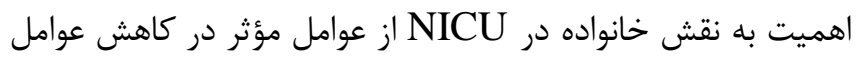

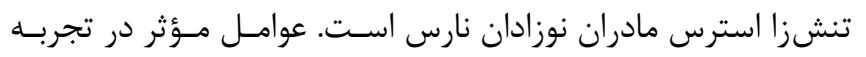

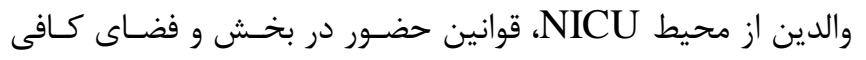

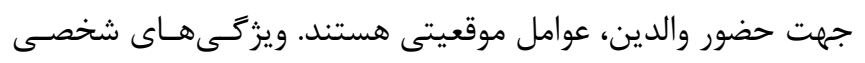
والدين از جمله افسردكى و اضطراب و منابع شخصى، منابع استرس هوس

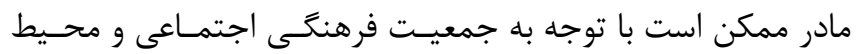

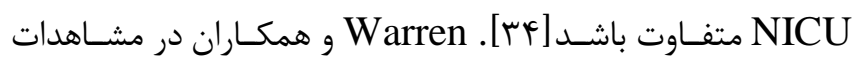

\section{بحث و نتيجه گيرى}

با توجه به معيارهاى انجمن روانيزشكى آمريكا و راهنماى تشخيصى

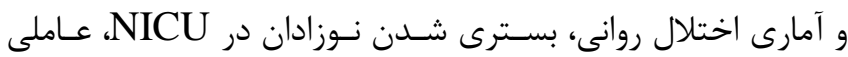

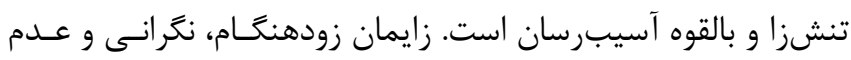

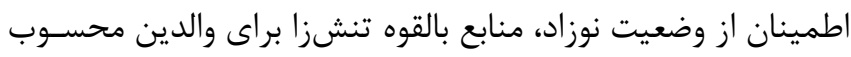

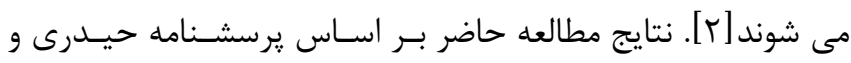

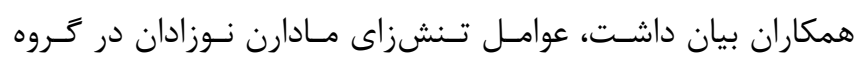

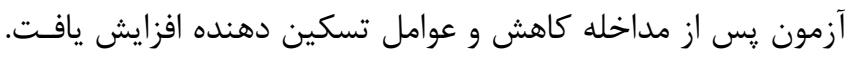

اين نتايج بر مؤثر واقع شدن برنامه مراقبت-حمايتى اشاره دارد.

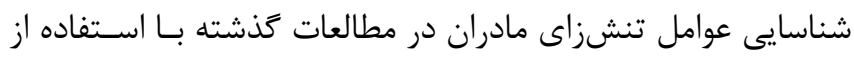
يرسشنامه مـايلز و همكـاران(Parental Stressor Scale:PSS) صورت كرفته. مايلز (Miels) و همكاران نشان دادند كه خـانوادههـا

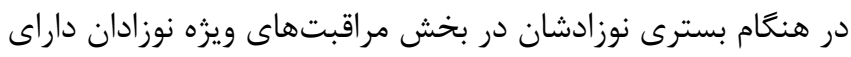

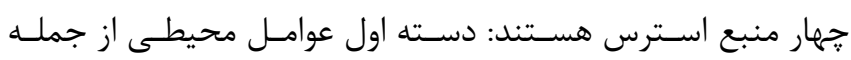

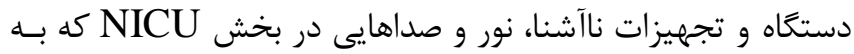

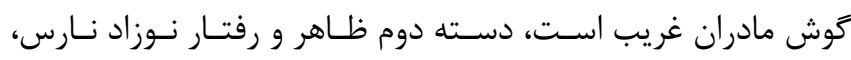

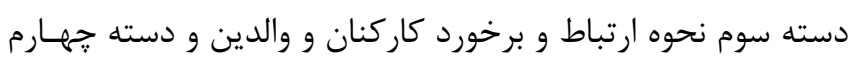

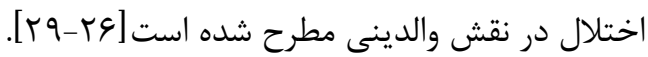
Caporali

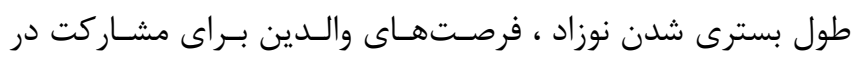

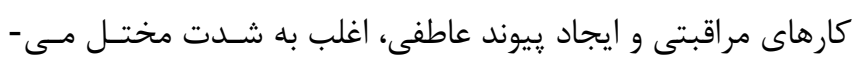

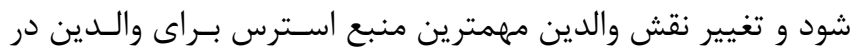

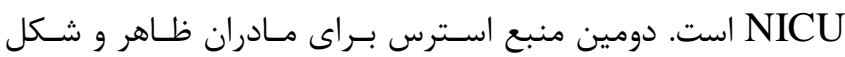

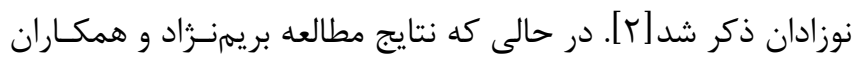

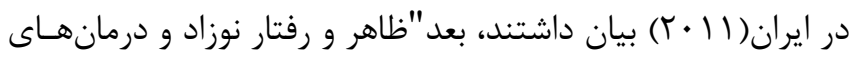

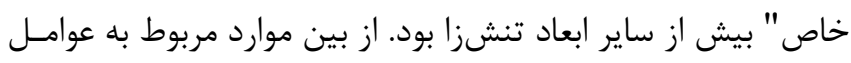

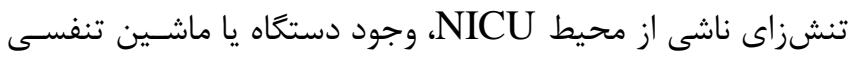

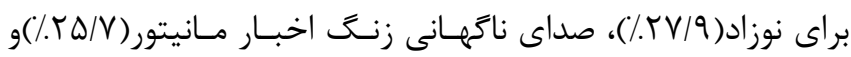

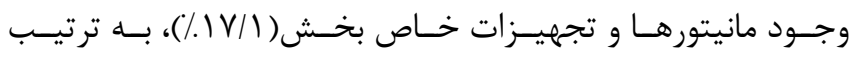

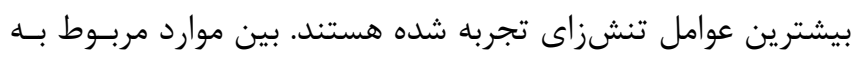

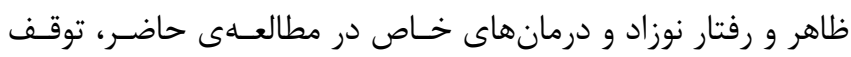

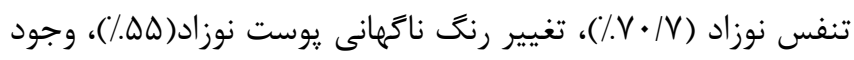

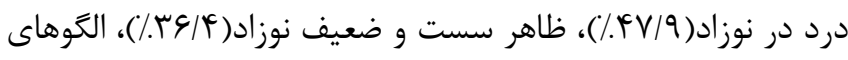

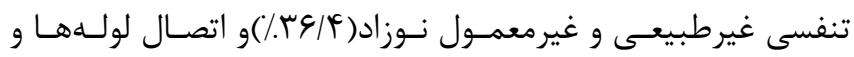

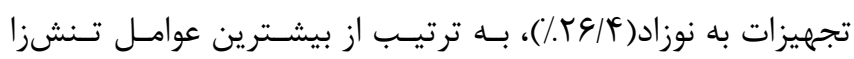

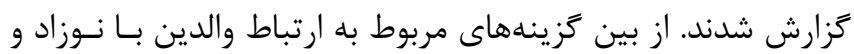


همكاران تحت عنوان تبيين مفهوم تنش والدينى در NICU با ارائه

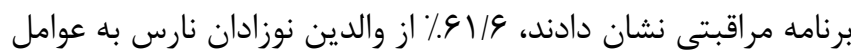

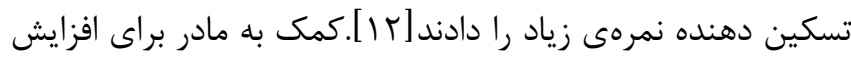

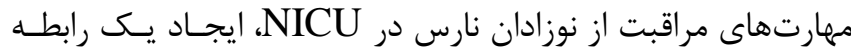

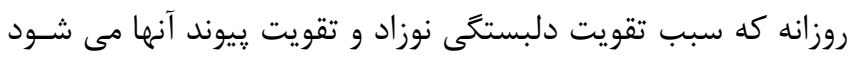

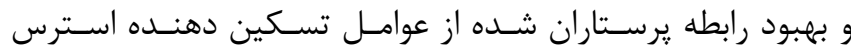

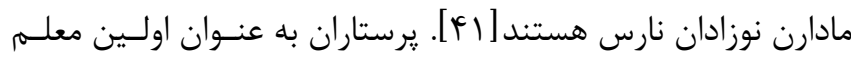

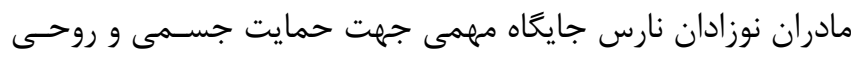

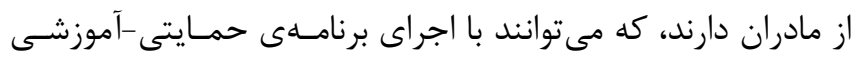

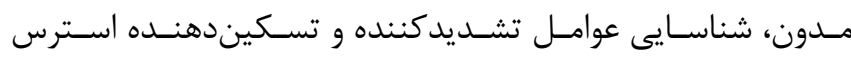

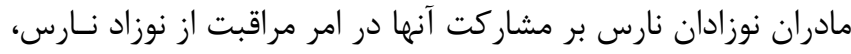

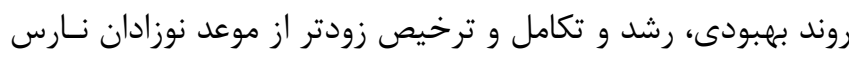

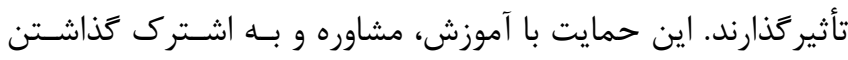
اطلاعات به صورت كلامى و نوشتارى تحقق بيدا مى كند. يافتههـاى

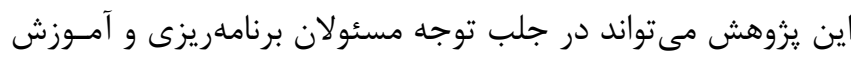

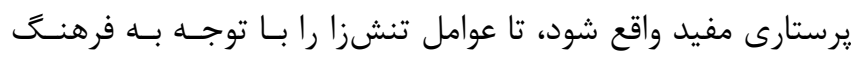

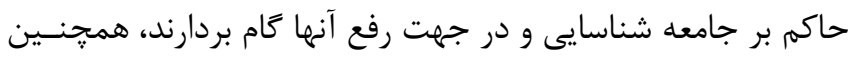

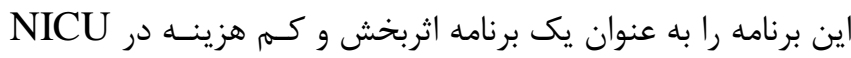

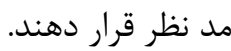

\section{سمم نويسند} شيما حيدرى: نوشتن طرح، اجرا و نغارش مقاله هايده حيدرى: نوشتن طرح، اجرا و نعارش مقاله رويا جويانى: همكارى در اجراى طرح

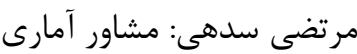

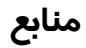

1. Benzies KM, Shah V, Aziz K, Isaranuwatchai W, Palacio-Derflingher L, Scotland J, et al. Family Integrated Care [FICare] in Level II Neonatal Intensive Care Units: study protocol for a cluster randomized controlled trial. Trials 2017;18:467-489

2. Caporali C, Pisoni C, Gasparini L, Ballante E, Zecca M, Orcesi S, et al. A global perspective on parental stress in the neonatal intensive care unit: a meta-analytic study. Journal of Perinatology 2020;40: 1739-1752

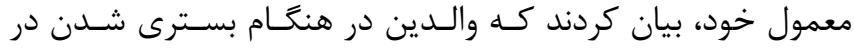

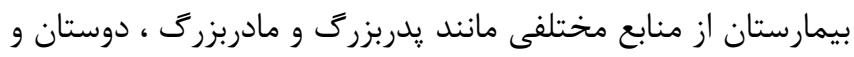

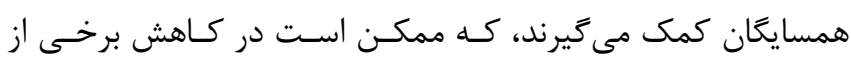

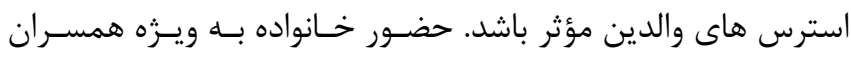

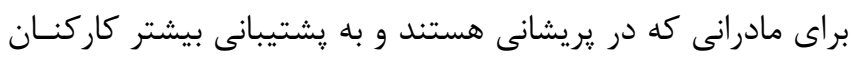

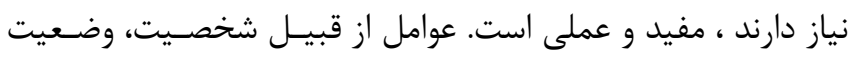

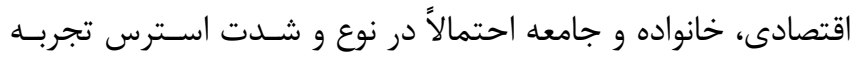

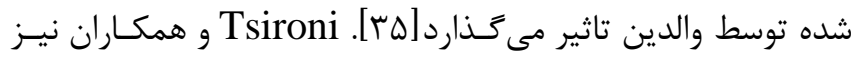

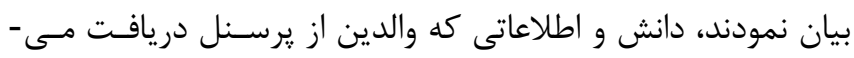

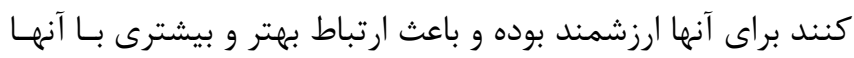

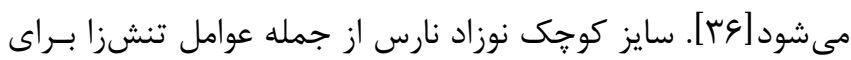

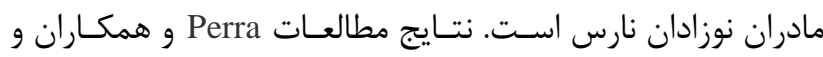

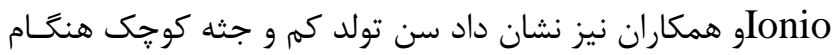

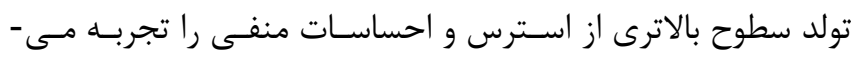

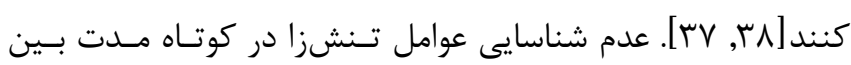

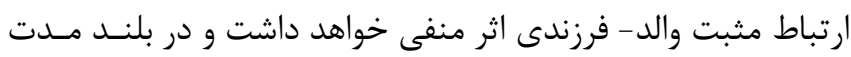

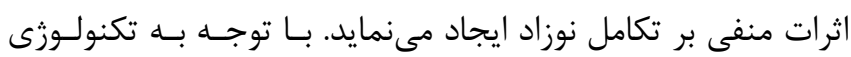

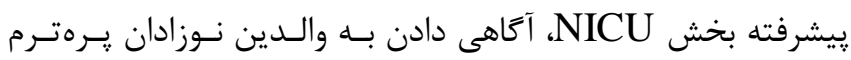

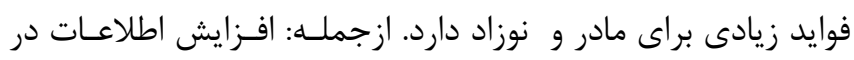

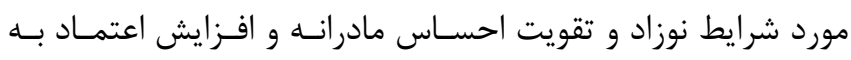

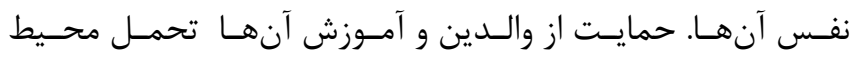

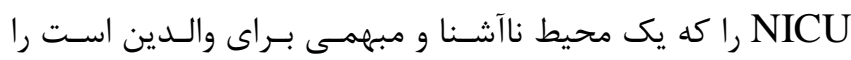

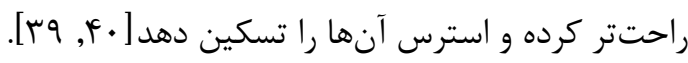

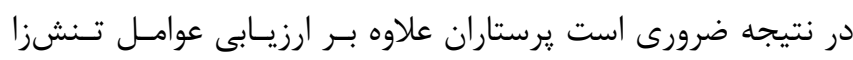

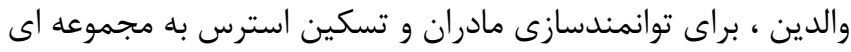

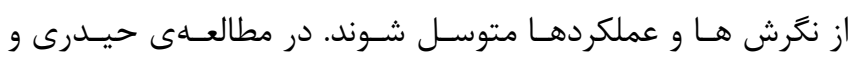

3. Malakouti J, Jabraeeli $\mathrm{M}$, valizadeh $\mathrm{s}$, babapour j. Mothers'experience of having a preterm infant in the neonatal intensive care unit, a Phenomenological Study 2013;5:172-181[Persion]

4. Pichler-Stachl E, Urlesberger P, Mattersberger C, Baik-Schneditz N, Schwaberger B, Urlesberger B, et al. Parental Stress Experience and Age of Mothers and Fathers After Preterm Birth and Admission of Their Neonate to Neonatal Intensive Care Unit; A Prospective Observational Pilot Study. Frontiers in Pediatrics 2019;7:3 
5. Bialoskurski MM, Cox C, Wiggins R. The relationship between maternal needs and priorities in a neonatal intensive care environment. Journal of Advanced Nursing 2002;37:9-62

6. Sajadi H, Akhoundzadeh G, Hojjati H. The Effect of Empowerment Program on Participation of Mothers with Premature Infants Hospitalized in Neonatal Intensive Care Unit of Sayyed Shirazi Hospital in Gorgan, in 2018. Indian Journal of Forensic Medicine \& Toxicology 2020;14:1269-1276 [Persion]

7. Wereszczak J, Miles MS, Holditch-Davis D. Maternal recall of the neonatal intensive care unit. Neonatal Network 1997;16:33-40

8. Mercer RT. Becoming a mother versus maternal role attainment. Journal of nursing scholarship 2004;36:226-232

9. Bandura A. Human agency in social cognitive theory. American Psychologist 1989;44:11-75

10. Strecher VJ, McEvoy DeVellis B, Becker MH, Rosenstock IM. The role of self-efficacy in achieving health behavior change. Health Education Quarterly 1986;13:73-92

11. Heidarzadeh A, Azizzadeh Forouzi M, Taheri Z, Dehghan M. Study of effect of Educational program on stress of parents of premature infants in neonatal intensive care units A Clinical Trial. Iranian Journal of Pediatric Nursing 2019;5:18-25 [Persion]

12. Heidari H, Hasanpour M, Fooladi M, Awat F. Construction of a Questionnaire to Assess Parental Stress in Neonatal Intensive Care Unit. Iranian Journal of Neonatology (IJN) 2015;6:6-12 [Persion]

13. Korahroudi FA, Shakibifard M, Nikfarid L, Nasiri M, Nouriyan M, Farahani ASA. The Effect of Empowering Mothers of Infants Hospitalized at the Neonatal Intensive Care Unit on Their Participation in Neonatal Care. Advances in Nursing \& Midwifery 2018;27:26-31 [Persion]

14. Benedetto L, Ingrassia M. Parental Selfefficacy in Promoting Children Care and Parenting Quality: InTech 2018: 6th. Academic Publishers: The Londen, Available from: https://app.dimensions.ai/details/publication/pub.1100 897815

15. Rasti M, Aliabadi F.F, Shafarodi N, Rafiee, F, Kalani, M. Specification of the educational needs of parents with premature infants admitted to neonatal intensive care unit. Mod Rehab 2014;8:21-9 [Persian] 16. Brett J, Staniszewska S, Newburn M, Jones, $\mathrm{N}$, Taylor L. A systematic mapping review of effective interventions for communicating with, supporting and providing information to parents of preterm infants. BMJ 2011;12:3

17. Heidary S, Heidari $\mathrm{H}$, Choopani R. Development of an educational content for mothers of premature infants admitted to the neonatal intensive care unit in Iran: a narrative review. International Journal of Epidemiology and Health Sciences 2021;2:1-11

18. Association IN. Infant Care Guide. Center YPiR, editor. $1^{\text {st }}$ Edition; Teb gostar:Yazd, 2015 [Persian]

19. Nore shdkam M, Nore shadkam Z. Premature infant care. Yazd: 1st Edition; Teb gostar:Yazd, 2015 [Persian]

20. Fraser D. Understanding the NICU: What Parents of Preemies and Other Hospitalized Newborns Need to Know. Neonatal network: 2017;36:321

21. Leahy-Warren P, McCarthy G. Maternal parental self-efficacy in the postpartum period. Midwifery 2011;27:802-810

22. Prasopkittikun T, Tilokskulchai F, Sinsuksai N, Sitthimongkol Y. Self efficacy in Infant Care Scale: Development and psychometric testing. Nursing \& Health Sciences 2006;8:44-50

23. Azhare S, Bghane R, Akhlaghe F, Ebrahimzadeh S, Salehi Fedardi J. Comparison of the effect of two methods of breastfeeding education with and without direct intervention of the educator on the level of breastfeeding self-efficacy in primiparous mothers. Sabzevar University of Medical Sciences (asrar) 2011;17:54-58 [Persion]

24. Samra HA, McGrath JM, Fischer S, Schumacher B, Dutcher J, Hansen J. The NICU parent risk evaluation and engagement model and instrument [PREEMI] for neonates in intensive care units. Journal of Obstetric, Gynecologic \& Neonatal Nursing 2015;44:114-126

25. Young Seok L, Garfield C, Hyung Nam K, editors. Self-efficacy theory as a framework for interventions that support parents of NICU infants. 2012 6th International Conference on Pervasive Computing Technologies for Healthcare [PervasiveHealth] and Workshops 2012: 151-154

26. Miles MS, Funk SG, Kasper MA .The stress response of mothers and fathers of preterm infants. Research in Nursing \& Health 1992;15:261-269

27. Sloan K, Rowe J, Jones L. Stress and coping in fathers following the birth of a preterm infant. Journal of Neonatal Nursing 2008;14:108-115 
28. Paul IM, Downs DS, Schaefer EW, Beiler JS, Weisman CS. Postpartum anxiety and maternal-infant health outcomes. Pediatrics 2013;131:e1218-1224

29. Busse M, Stromgren K, Thorngate L, Thomas KA. Parents' Responses to Stress in the Neonatal Intensive Care Unit. Critical care nurse 2013;33:9-52

30. Borim Nejad L, Mehrnosh N, Seyyed Fatemi, Haghghani H. Maternal Stressor Agents with Premature Infants in Neonatal Intensive Care Units. Journal of Critical Care Nursing 2011;4:39-49 [Persion]

31. Hosseini SS, Baniasadi H, Pouraboli B. Stressors of Parents of Hospitalized Preterm Infants: a study in Neonatal Intensive Care Unit of Afzalipour Hospital, Kerman, Iran. Health and Development Journal 2015;4:337-348 [Persion]

32. Baía I, Amorim M, Silva S, Kelly-Irving M, de Freitas C, Alves E. Parenting very preterm infants and stress in Neonatal Intensive Care Units. Early Human Development 2016;101:3-9

33. Mehdizadeh S, Abbasi S. The parental stress sources and some related factors in mothers of premature s Infants in Neonatal Intensive Care Units. Iranian Journal of Pediatric Nursing 2019;5:44-50 [Persion]

34. Varma JR, Nimbalkar SM, Patel D, Phatak AG. The Level and Sources of Stress in Mothers of Infants Admitted in Neonatal Intensive Care Unit. Indian Journal of Psychological Medicine 2019;41:338-342

35. Leahy-Warren $\mathrm{P}$, Coleman C, Bradley R, Mulcahy $\mathrm{H}$. The experiences of mothers with preterm infants within the first-year post discharge from NICU: social support, attachment and level of depressive symptoms. BMC Pregnancy and Childbirth 2020;20:1-10

36. Tsironi $\mathrm{S}$, Bovaretos $\mathrm{N}$, Tsoumakas $\mathrm{K}$, Giannakopoulou M, Matziou V. Factors affecting parental satisfaction in the neonatal intensive care unit. Journal of Neonatal Nursing 2012;18:183-192

37. Ionio C, Mascheroni E, Colombo C, Castoldi F, Lista G. Stress and feelings in mothers and fathers in NICU: identifying risk factors for early interventions. Primary Health Care Research \& Development 2019;20:1-7

38. Perra O, Wass S, McNulty A, Sweet D, Papageorgiou KA, Johnston M, et al. Very preterm infants engage in an intervention to train their control of attention: results from the feasibility study of the Attention Control Training [ACT] randomised trial. Pilot and Feasibility Studies 2021;7:1-23

39. Altimier L, Phillips RM .The neonatal integrative developmental care model: seven neuroprotective core measures for family-centered developmental care. Newborn and Infant Nursing Reviews 2013;13:9-22

40. Büssing A, Waßermann U, Christian Hvidt N, Längler A, Thiel M. Spiritual needs of mothers with sick new born or premature infants - A cross sectional survey among German mothers. Women and Birth 2018;31:e89-e98

41. Fróes GF, Mendes ENW, Pedroza GA, Cunha M. Stress experienced by mothers of preterm newborns in a neonatal intensive care unit. Revista Gaúcha de Enfermagem (RGE) 2020;41:e20190145 